ERRATUM

doi:10.1038/nature1 1457

\title{
Erratum: Stereospecific binding of a disordered peptide segment mediates BK channel inactivation
}

Vivian Gonzalez-Perez, Xu-Hui Zeng, Katie Henzler-Wildman \& Christopher J. Lingle

Nature 485, 133-136 (2012); doi:10.1038/nature10994.

In this Letter, Fig. $2 \mathrm{~h}$ displays minimal models for recovery from inactivation to guide thinking about the associated single-channel behaviours for control (top trace), in the presence of L-peptide (next two traces), and in the presence of D-peptide (bottom two traces). The model for recovery from inactivation by the L-peptide inadvertently read $\mathrm{I}^{*} \rightleftharpoons \mathrm{O}^{*} \rightarrow \mathrm{C} \rightarrow \mathrm{C}$ instead of $\mathrm{I}^{*} \rightleftharpoons \mathrm{O}^{*} \rightarrow \mathrm{O} \rightarrow \mathrm{C}$. This error has no effect on any of our analyses or conclusions. Figure $2 \mathrm{~h}$ has been corrected in the PDF and HTML versions of this Letter. 